\title{
Control and benefits of CP4-57 prophage excision in Escherichia coli biofilms
}

\author{
Xiaoxue Wang ${ }^{1}$, Younghoon Kim ${ }^{1}$ and Thomas K Wood ${ }^{1,2,3}$ \\ ${ }^{1}$ Artie McFerrin Department of Chemical Engineering, Texas A\&M University, College Station, TX, USA; \\ ${ }^{2}$ Department of Biology, Texas A\&M University, College Station, TX, USA and ${ }^{3}$ Zachry Department of Civil \\ Engineering, Texas A\&M University, College Station, TX, USA
}

\begin{abstract}
Earlier, we discovered that the global regulator, Hha, is related to cell death in biofilms and regulates cryptic prophage genes. Here, we show that Hha induces excision of prophages, CP4-57 and DLP12, by inducing excision genes and by reducing SsrA synthesis. SsrA is a tmRNA that is important for rescuing stalled ribosomes, contains an attachment site for CP4-57 and is shown here to be required for CP4-57 excision. These prophages impact biofilm development, as the deletion of 35 genes individually of prophages, CP4-57 and DLP12, increase biofilm formation up to 17-fold, and five genes decrease biofilm formation up to sixfold. In addition, CP4-57 excises during early biofilm development but not in planktonic cells, whereas DLP12 excision was detected at all the developmental stages for both biofilm and planktonic cells. CP4-57 excision leads to a chromosome region devoid of prophage and to the formation of a phage circle (which is lost). These results were corroborated by a whole-transcriptome analysis that showed that complete loss of CP4-57 activated the expression of the $\mathrm{flg}$, flh and fli motility operons and repressed expression of key enzymes in the tricarboxylic acid cycle and of enzymes for lactate utilization. Prophage excision also results in the expression of cell lysis genes that reduce cell viability (for example, alpA, intA and intD). Hence, defective prophages are involved in host physiology through Hha and in biofilm formation by generating a diversified population with specialized functions in terms of motility and nutrient metabolism.
\end{abstract}

The ISME Journal (2009) 3, 1164-1179; doi:10.1038/ismej.2009.59; published online 21 May 2009

Subject Category: microbe-microbe and microbe-host interactions

Keywords: Hha; SsrA; CP4-57; DLP12; biofilms; prophage

\section{Introduction}

The battle between host and phage is epic, but may cease for the benefit of both. Lytic phages such as T4 invade, lyse their host and exit as victors. Temperate phages such as lambda decide when to integrate and when to lyse the host, and the integration/excision (Int/Xis) system is encoded by its own genes but works with a host-encoded integration factor (Cho et al., 2002). Once integrated into the host, temperate phage and host reach an equilibrium when a balance between the costs and benefits to both is achieved (Chen et al., 2005). For the host, integration of phages increases the ecological fitness of many bacteria; for example, integration prevents further phage invasion, increases serum resistance and helps the bacterium to invade or evade its host through toxins or adhesions (Chen et al., 2005). For the phage, it benefits by passage to bacterial progeny

Correspondence: TK Wood, Artie McFerrin Department of Chemical Engineering, Texas A\&M University, 220 JE Brown Building, 3122 TAMU, College Station, TX 77843-3122, USA.

E-mail: Thomas.Wood@chemail.tamu.edu

Received 2 March 2009; revised 17 April 2009; accepted 21 April 2009; published online 21 May 2009 during chromosome replication and leaves when the environment is not favorable.

Prophage-like elements and prophage remnants have been identified in almost all sequenced bacterial genomes (Canchaya et al., 2003) and can constitute $10-20 \%$ of a bacterium's genome (Casjens, 2003). Attempts to identify prophage excision under various environments have shown very low frequencies of excision (Sozhamannan et al., 2006), indicating a stable residence of prophage under most conditions. The widespread and relatively stable existence of these prophages in bacteria indicates that the battle between host and these phages has ceased under normal growth conditions.

Integration of prophage into the bacterium often causes coevolution of the host and phage (Canchaya et al., 2003; de Mello Varani et al., 2008). In this case, the prophages have capitulated to the host, and it is reasonable for the host to gain more control of the prophage by modulating the expression of its genes. There is evidence that the prophage accumulates major mutations rapidly by undergoing a complex decay process (Canchaya et al., 2003; Casjens, 2003). These mutations render the prophages defective in functions that are detrimental to 
the host, whereas, at the same time, maintaining or enhancing the functions that are beneficial to the host (Canchaya et al., 2003; Casjens, 2003).

Phage-encoded integrase is among the most conserved prophage genes as shown by comparative genomics (Lindsey et al., 1989; Boyd and Brüssow, 2002). Integrase is required for both integration and excision of prophage (Cho et al., 2002). Excision of the phage from the host genome requires another protein called excisionase (Xis) (Cho et al., 2002), and excision allows the expression of phage-encoded lytic genes (Kirby et al., 1994; Casjens, 2003). In many cases, Xis is no longer functional (for example, DLP12 in Escherichia coli K-12 (Lindsey et al., 1989)), and its inactivation indicates a loss of self-control by the prophage. For example, there is evidence that the excision of lambda is stimulated by the host factor for inversion stimulation (Thompson et al., 1987).

Biofilm formation is arguably the dominant lifestyle for most bacteria (Watnick and Kolter, 2000; Webb et al., 2003a), wherein the most important actions for shaping bacteria and their phage take place, which make it the ideal growth state to study host-phage interactions. Moreover, the role of prophage in biofilms has been receiving increasing attention. We observed induction of several clusters of prophage genes, including CP4-57 and DLP12, in mature biofilms of $E$. coli $\mathrm{K} 12$ using whole-transcriptome analysis (Domka et al., 2007). Prophage genes are among the most highly induced genes during biofilm development in both Gram-negative Pseudomonas aeruginosa (Whiteley et al., 2001) and E. coli (Herzberg et al., 2006; Domka et al., 2006, 2007; Lee et al., 2007; García-Contreras et al., 2008) as well as in Gram-positive Bacillus subtilis (Stanley et al., 2003; Ren et al., 2004a). In addition to differential expression, prophage excision has been linked to both cell death and lysis for $P$. aeruginosa cells in biofilms, as filamentous-like prophage excision increases diversity in dispersing cells and impacts biofilm architecture (Bayles, 2003; Webb et al., 2003b). However, little is known about the regulation of filamentous prophage excision (Bayles, 2003; Webb et al., 2003b). Moreover, self-generated diversity, including generating small-colony variants (SCVs), is important in biofilm formation (Boles et al., 2004; Webb et al., 2004); yet, the genetic basis of the emergence of SCVs is largely unknown.

E. coli K-12 has served as a model organism in the field of biochemical genetics, molecular biology and biotechnology (Blattner et al., 1997). When isolated, E. coli K-12 carried the bacteriophage lambda plus the defective lambdoid prophages, CP4-57, DLP12, Rac and Qin, and the element, e14 (Blattner et al., 1997). Of these, CP4-57 (Kirby et al., 1994) and DLP12 (Lindsey et al., 1989) are two of the bestcharacterized cryptic prophages. CP4-57 is a putative defective prophage with 22 genes and 4 pseudogenes; however, it lacks both a signature capsid and assembly genes (http://www.ecogene. org/). DLP12 is a defective prophage with 22 genes and 10 pseudogenes, including both P22 and lambda phage modules (http://www.ecogene.org/). These two cryptic prophages have lost some functions essential for lytic growth but still retain some functional phage genes (Blattner et al., 1997), including int $A$ and alpA of CP4-57 (Kirby et al., 1994), and intD, ompT, ybcS and essD of DLP12 (Lindsey et al., 1989; Srividhya and Krishnaswamy, 2007).

To understand how hosts control the gene expression of captured prophage, it is essential to identify the host factors that promote prophage excision. The chromosomal hha gene (high hemolysin activity) of $E$. coli was first identified in a search for mutants that overproduced the toxin, $\alpha$-hemolysin, from a plasmid-encoded hemolytic hly operon of E. coli strain 5K (Carmona et al., 1993). Hha is a small transcriptional regulator $(8 \mathrm{kDa})$ that we discovered is induced in biofilms (Ren et al., 2004c) and that we found influences biofilm formation (González Barrios et al., 2006b); Hha overexpression reduces biofilm formation by increasing biofilm dispersal (García-Contreras et al., 2008). Rather than binding to specific DNA sequences, Hha exhibits nonspecific DNA binding (Nieto et al., 2000). We found that Hha binds in vivo to 15 genes or to intergenic regions of CP4-57 and DLP12 including regions close to the prophage attachment (att) sites and that Hha activates the prophage lytic genes alpA, $r z p D, a p p Y$ and $y f j Z$, as well as induces plaque formation and decreases cell viability (García-Contreras et al., 2008). Therefore, we hypothesized that Hha is involved in the regulation of prophage excision, including CP4-57 and DLP12, and that this excision would influence biofilm formation.

The aims of this study were to determine the functions of prophage in the life cycle of a biofilm, to test whether prophage excision occurs in biofilms and to explore the mechanism controlling prophage excision and gene expression. We also explore whether prophage excision is involved in population diversification in biofilms and address what are the benefits for bacteria that harbor prophages. Using $E$. coli as a reference system, we found that prophages, CP4-57 and DLP12, excise in biofilms, that Hha controls their excision and that excision of CP4-57 reduces cell fitness and affects biofilm formation.

\section{Materials and methods}

Bacterial strains, plasmids and growth conditions The isogenic E. coli BW25113 strains and plasmids used in this study are listed in Table 1. For deleting and overexpressing genes, we used the Keio collection (Baba et al., 2006) and the ASKA library (Kitagawa et al., 2005). Experiments were conducted at $37^{\circ} \mathrm{C}$ in either Luria-Bertani medium (LB) (Sambrook et al., 1989), LB containing $0.2 \%$ glucose (LB glu), M9 minimal medium with $0.2 \%$ casamino 
Table 1 E. coli $\mathrm{K}-12$ bacterial strains and plasmids used in this study

\begin{tabular}{|c|c|c|}
\hline Strains and plasmids & Genotype/relevant characteristics & Source \\
\hline \multicolumn{3}{|l|}{ Strains } \\
\hline BW25113 & $\operatorname{lacl}^{4} \operatorname{rrnB}_{\mathrm{T} 14} \Delta \operatorname{lac}_{\mathrm{W} 16} h s d R 514 \Delta a r a B A D_{\mathrm{AH} 33} \Delta r h a B A D_{\mathrm{LD} 78}$ & Baba et al. (2006) \\
\hline BW25113 $\Delta$ CP4-57 & BW25113 lacking chromosomal CP4-57 genes and circle & This study \\
\hline BW25113 $\Delta$ CP4-57 $7^{\text {circle }}$ & BW25113 $\Delta \mathrm{CP} 4-57$ with phage circle CP4-57 $\Delta a l p A \Omega \mathrm{Km}^{\mathrm{R}}$ & This study \\
\hline BW25113 SSrA & BW25113 $\Delta s s r A \Omega \mathrm{Km}^{\mathrm{R}}$ & This study \\
\hline BW25113 ssrA $\mathrm{attL}^{+}$ & BW25113 $\Delta s s r A$ (partial deletion with attL intact) $\Omega \mathrm{Km}^{\mathrm{R}}$ & This study \\
\hline BW25113 hha & BW25113 $\Delta h h a \Omega \mathrm{Km}^{\mathrm{R}}$ & Baba et al. (2006) \\
\hline BW25113 alp A & BW25113 $\Delta$ alpA $\Omega \mathrm{Km}^{\mathrm{R}}$ & Baba et al. (2006) \\
\hline BW25113 intA & BW25113 $\Delta$ int $A \Omega \mathrm{Km}^{\mathrm{R}}$ & Baba et al. (2006) \\
\hline BW25113 intD & $\mathrm{BW} 25113 \Delta$ intD $\Omega \mathrm{Km}^{\mathrm{R}}$ & Baba et al. (2006) \\
\hline BW25113 appY & $\mathrm{BW} 25113 \Delta a p p Y \Omega \mathrm{Km}^{\mathrm{R}}$ & Baba et al. (2006) \\
\hline BW25113 borD & BW25113 $\Delta$ borD $\Omega \mathrm{Km}^{\mathrm{R}}$ & Baba et al. (2006) \\
\hline BW25113 essD & BW25113 $\Delta e s s D \Omega \mathrm{Km}^{\mathrm{R}}$ & Baba et al. (2006) \\
\hline BW25113 ompT & BW25113 $\Delta o m p T \Omega \mathrm{Km}^{\mathrm{R}}$ & Baba et al. (2006) \\
\hline BW25113 rzpD & $\mathrm{BW} 25113 \Delta r z p D \Omega \mathrm{Km}^{\mathrm{R}}$ & Baba et al. (2006) \\
\hline BW25113 ybcS & BW25113 $\Delta y b c S \Omega \mathrm{Km}^{\mathrm{R}}$ & Baba et al. (2006) \\
\hline BW25113 hha ssrA attL $L^{+}$ & BW25113 $\Delta h h a \Delta s s r A$ attL ${ }^{+} \Omega \mathrm{Km}^{\mathrm{R}}$ & This study \\
\hline \multicolumn{3}{|l|}{ Plasmids } \\
\hline pCA24N & $\mathrm{Cm}^{\mathrm{R}} ; \operatorname{lacl}^{\mathrm{q}}, \mathrm{pCA} 24 \mathrm{~N}$ & Kitagawa et al. (2005) \\
\hline pCA24N-hha & $\mathrm{Cm}^{\mathrm{R}} ; \operatorname{lacl}^{\mathrm{q}}$, pCA24N $\mathrm{P}_{\mathrm{T} 5 \text {-lac }}: h h a^{+}$ & Kitagawa et al. (2005) \\
\hline pCA24N-int A & $\mathrm{Cm}^{\mathrm{R}} ;$ lacl $\mathrm{I}^{\mathrm{q}}$, pCA24N $\mathrm{P}_{\mathrm{T} 5 \text {-lac }}:$ int $A^{+}$ & Kitagawa et al. (2005) \\
\hline pCA24N-alpA & $\mathrm{Cm}^{\mathrm{R}} ;$ lac I ${ }^{\mathrm{q}}$, pCA24N $\mathrm{P}_{\mathrm{T} 5 \text {-lac }}:$ alp $A^{+}$ & Kitagawa et al. (2005) \\
\hline pCA24N-intD & 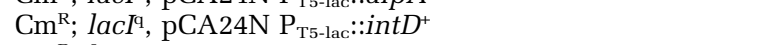 & Kitagawa et al. (2005) \\
\hline pCA24N-ypjF & $\mathrm{Cm}^{\mathrm{R}} ;$ lacl $^{\mathrm{T}}, \mathrm{pCA} 24 \mathrm{~N} \mathrm{P}_{\mathrm{T} 5 \text {-lac }}:: y p j F^{+}$ & Kitagawa et al. (2005) \\
\hline pCA24N-app $Y$ & $\mathrm{Cm}^{\mathrm{R}} ; \operatorname{lacl}^{\mathrm{T}}, \mathrm{pCA} 24 \mathrm{~N} \mathrm{P}_{\mathrm{T} 5-\mathrm{lac}}:: a p p Y^{+}$ & Kitagawa et al. (2005) \\
\hline pCA24N-borD & $\mathrm{Cm}^{\mathrm{R}} ; \operatorname{lacl}^{\mathrm{q}}$, pCA24N $\mathrm{P}_{\mathrm{T} 5 \text {-lac }}:: b o r D^{+}$ & Kitagawa et al. (2005) \\
\hline pCA24N-essD & $\mathrm{Cm}^{\mathrm{R}} ; \operatorname{lacI}^{\mathrm{q}}, \mathrm{pCA} 24 \mathrm{~N} \mathrm{P}_{\mathrm{T} 5 \text {-lac }}:: e s s D^{+}$ & Kitagawa et al. (2005) \\
\hline pCA24N-ompT & $\mathrm{Cm}^{\mathrm{R}} ;$ lacI $^{\mathrm{q}}, \mathrm{pCA} 24 \mathrm{~N} \mathrm{P}_{\mathrm{T} 5 \text {-lac }}:: o m p T^{+}$ & Kitagawa et al. (2005) \\
\hline pCA24N-rzpD & $\mathrm{Cm}^{\mathrm{R}} ; \operatorname{lacl}^{\mathrm{I}}, \mathrm{pCA} 24 \mathrm{~N} \mathrm{P}_{\mathrm{T} 5 \text {-lac }}:: r z p D^{+}$ & Kitagawa et al. (2005) \\
\hline pCA24N-ybcS & $\mathrm{Cm}^{\mathrm{R}} ;$ lacl $^{\mathrm{q}}, \mathrm{pCA} 24 \mathrm{~N} \mathrm{P}_{\mathrm{T5} \text {-lac }}:: y b c S^{+}$ & Kitagawa et al. (2005) \\
\hline
\end{tabular}

$\mathrm{Km}^{\mathrm{R}}$ and $\mathrm{Cm}^{\mathrm{R}}$ are kanamycin and chloramphenicol resistance, respectively. There are an additional 31 BW25113 deletion strains used for the biofilm studies (Figure 1) that are not listed here for brevity.

acids (M9C) (Rodriguez and Tait, 1983) or M9C with $0.1 \%$ lactate (M9C lactate). Kanamycin $\left(50 \mu \mathrm{g} \mathrm{ml}^{-1}\right)$ was used for preculturing isogenic knockout mutants, and chloramphenicol $\left(30 \mu \mathrm{g} \mathrm{ml}^{-1}\right)$ was used for maintaining pCA24N-based plasmids.

Construction of BW25113 ssrA, ssrA attL $\mathrm{L}^{+}$and hha ssrA attL ${ }^{+}$

For mutant BW25113 ssrA, the whole region encoding the transcript of SsrA as well as its promoter region was deleted from the chromosome using a one-step inactivation procedure described previously (Baba et al., 2006), with primers, delta $s s r A-f$ and delta ssrA-r (Table 2), as previously designed, to remove ssrA from E. coli MG1655 (Christensen and Gerdes, 2003). For the construction of the partial SsrA mutant, BW25113 ssrA $a t t L^{+}$, primers, delta $s s r A-f$ and delta $s s r A$ att $L^{+}-\mathrm{r}$ (Table 2), were used to remove the promoter region as well as a part of the $\operatorname{ssr} A$ transcript; however, the attL site was not removed. The sequences near the deletions in these two mutants were verified by DNA sequencing from PCR fragments using primers flanking the upstream gene, $\operatorname{smp} B$ (delta $s s r A-\mathrm{U}$ ), and the downstream gene, intA (delta $s s r A-D$ ) (Table 2), of $s s r A$, as described previously (Baba et al., 2006). Double mutant BW25113 hha ssrA $a t t L^{+}$was constructed as described previously through bacteriophage P1 transduction (Maeda et al., 2008) to transfer the hha deletion from the Keio collection to $s s r A$ attL $L^{+}$.

\section{Growth assays}

The growth of the BW25113 wild-type strain and the CP4-57 deletion mutant was determined using turbidity measurements at $600 \mathrm{~nm}$ with $\mathrm{LB}, \mathrm{LB}$ glu, M9C and M9C lactate. In addition, the toxicity of selected prophage proteins was investigated using pCA24N-based expression plasmids (Kitagawa et al., 2005), with $1 \mathrm{mM}$ isopropyl- $\beta-D$-thiogalactopyranoside (IPTG) added at a turbidity of 0.5 at $600 \mathrm{~nm}$ (for RzpD, $2 \mathrm{mM}$ IPTG was also added at a turbidity of $0.3,0.8$ and 1.8 , at $600 \mathrm{~nm}$ ). Cells were diluted by $10^{2}-10^{7}$, using 10 -fold serial dilution steps, into $0.85 \% \mathrm{NaCl}$ solution and plated on LB agar including chloramphenicol to determine cell viability (Donegan et al., 1991).

\section{Crystal violet biofilm assay and CFU count of biofilm cells}

Biofilm formation was assayed in 96-well polystyrene plates (Corning Costar, Cambridge, MA, USA), as described previously, with crystal violet staining (Pratt and Kolter, 1998). To remove growth effects, we normalized biofilm formation by dividing total biofilm by the maximal bacterial growth as mea- 
Table 2 Nucleotide sequences and expected size of the primer sets used in this study

\begin{tabular}{|c|c|c|}
\hline Primer name & Primer sequence (listed $5^{\prime}$ to $3^{\prime}$ ) & $\begin{array}{l}\text { Expected } \\
\text { size (bp) }\end{array}$ \\
\hline \multicolumn{3}{|l|}{ Sequencing } \\
\hline CP4-57f & AAGCACATAAACCTGGTTCAGCGAC & \multirow[t]{2}{*}{$1219^{\mathrm{a}}$} \\
\hline $\mathrm{CP} 4-57 \mathrm{r}$ & TAGCTGGTGTGAACTGGTCGTTCTG & \\
\hline DLP12f & CATAATGATCACCGACGTTGGTTTC & \multirow[t]{2}{*}{$768^{\mathrm{a}}$} \\
\hline DLP12r & GTATTGTCTAACTTTCTTGAGCAATCG & \\
\hline CP4-57-Cf & AGTGGCTGTCTGGCAAATG & \multirow[t]{2}{*}{$850^{\mathrm{a}}$} \\
\hline CP4-57-Cr & TCCGATATTTACACTAGGAACAGC & \\
\hline \multicolumn{3}{|l|}{$q P C R$} \\
\hline CP4-57-2f & AAGCATGTAGTACCGAGGATGTAGG & \multirow[t]{2}{*}{151} \\
\hline CP4-57-2r & TATGTCTCCTCACCGTCTGGTCGG & \\
\hline DLP12-2f & CAAAAGCCATTGACTCAGCAAGG & \multirow[t]{2}{*}{175} \\
\hline DLP12-2r & ACGGATAAGACGGGCATAAATGA & \\
\hline purA_f & GGGCCTGCTTATGAAGATAAAGT & \multirow{2}{*}{209} \\
\hline purA_r & TCAACCACCATAGAAGTCAGGAT & \\
\hline \multicolumn{3}{|l|}{$q R T-P C R$} \\
\hline $\operatorname{alp} A$ & GAACAATCGATCGGCCGTT & \multirow[t]{2}{*}{181} \\
\hline & CTCATCAATCTCGGCCTCA & \\
\hline \multirow[t]{2}{*}{$\operatorname{int} A$} & TGAGATTAAGGCTCATACTCTGGTT & \multirow[t]{2}{*}{158} \\
\hline & TTCCGATATTTACACTAGGAACAGC & \\
\hline \multirow[t]{2}{*}{ intD } & GTCTGAGTTGATACTGGCTTTGGTT & \multirow[t]{2}{*}{288} \\
\hline & AAAGCTAGGGGATTTACCTGATGTC & \\
\hline \multirow[t]{2}{*}{$\operatorname{ssr} A$} & AAGAGTTCGAAGCGGGACTT & \multirow[t]{2}{*}{188} \\
\hline & TAACTTGCGGGTACGGGTAG & \\
\hline \multirow[t]{2}{*}{$\operatorname{rrs} G$} & TATTGCACAATGGGCGCAAG & \multirow[t]{2}{*}{232} \\
\hline & ACTTAACAAACCGCTGCGT & \\
\hline \multicolumn{3}{|c|}{ BW25113 ssrA mutant construction } \\
\hline delta $\operatorname{ssr} A-\mathrm{f}$ & $\begin{array}{l}\text { CGAATAAAAATCAGGCTACATGGGTGCTAAATCTTTAACGATAACG } \\
\text { CCGTGTAGGCTGGAGCTGCTTC }\end{array}$ & \\
\hline \multirow{2}{*}{ delta $\operatorname{ssr} A-\mathrm{r}$} & CTTAGGACTTCATCGGATGACTCTGGTAATCACCGATGGAGAATTTTG & \\
\hline & CATATGAATATCCTCCTTTAG & \\
\hline delta $\operatorname{ssr} A$ att $L^{+}-\mathrm{r}$ & GCTTCCACGCGATCTCTTTTGGGTTTGACCTCTCTTGATCCCCGTCCTC & \\
\hline delta $\operatorname{ssr} A-\mathrm{U}$ & AAGGAATATCLICLITTAG & $2274^{\mathrm{b}}$ or $2474^{\mathrm{c}}$ \\
\hline delta $\operatorname{ssr} A$-D & TTCCGTATCAGTTAACGGCTTGG & \\
\hline
\end{tabular}

$\mathrm{f}$ indicates forward primer and $\mathrm{r}$ indicates reverse primer.

${ }^{a}$ Size of amplified fragment upon deletion of prophage.

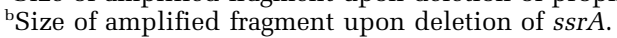

'Size of amplified fragment upon deletion of $s s r A$ attL'.

sured by turbidity at $620 \mathrm{~nm}$ for each strain. The total number of viable cells in a biofilm formed on $14 \mathrm{ml}$ polystyrene tubes (Becton Dickinson Labware, Franklin Lakes, NJ, USA) was determined by sonicating for $5 \mathrm{~min}$ at $22 \mathrm{~W}$ in an FS3 water bath sonicator (Fisher Scientific, Pittsburgh, PA, USA). The time for sonication was chosen to maximize the number of viable cells from the biofilm.

Quantitative real-time PCR

To determine the relative concentrations of specific DNA fragments, total DNA (50-200 ng) isolated using the UltraClean Microbial DNA Isolation Kit (Mo Bio Laboratories, Inc., Carlsbad, CA, USA) was used as the template for the quantitative real-time PCR (qPCR) using the SuperScript III Platinum SYBR Green One-Step qRT-PCR Kit (Invitrogen, Carlsbad, CA, USA). The reaction and analysis were carried out by the StepOne Real-Time PCR System (Applied Biosystems, Foster City, CA, USA). The relative amount of chromosomal DNA undergoing excision was calculated by comparing threshold cycle numbers of a target gene vs that of a reference gene (Pfaffl, 2001); the reference gene was adenylosuccinate synthase (purA). The number of chromosomes that are devoid of each prophage was quantified using primers flanking each prophage (primers CP4-57-2f/CP4-57-2r for CP4-57 and DLP12-2f/DLP12-2r for DLP12), which only give PCR products when the prophage is removed due to the size of the prophage. Genomic DNA from the $\Delta \mathrm{CP} 4-57$ strain was used as a template positive control for testing primer-binding efficiencies. The binding efficiencies of the primers used here were tested with varying template concentrations to generate a standard curve, and their validity of application in the quantification was confirmed for CP4-57 and for DLP12. Primer sets used for the reference gene (purA), for the chromosome that undergoes excision of CP4-57 (CP4-57-2f and CP457-2r) and for excision of DLP12 (DLP12-2f and DLP12-2r), are indicated in Table 2. 
Quantitative real-time reverse-transcription PCR

Different from the qPCR described above that determined the relative concentrations of specific DNA fragments, quantitative real-time reverse-transcription PCR (qRT-PCR) was used to quantify relative RNA concentrations using $50 \mathrm{ng}$ as a template and included a complementary DNA synthesis step from RNA before the denaturation step. Primers for qRT-PCR for $\operatorname{alp} A$, int $A$, int $D$ and ssr $A$ are listed in Table 2. The housekeeping gene, $\operatorname{rrs} G$ (16S rRNA gene), was used to normalize the gene expression data.

\section{$R N A$ isolation and whole-transcriptome studies}

For the $\Delta \mathrm{CP} 4-57$ vs BW25113 whole-transcriptome study, exponentially grown planktonic cells were collected when the cell density (turbidity at $600 \mathrm{~nm}$ ) reached 0.5. Total RNA was isolated as described previously (Ren et al., 2004c), using a bead beater (BioSpec, Bartlesville, OK, USA). The E. coli GeneChip Genome 2.0 array (Affymetrix, Santa Clara, CA, USA; P/N 4059655) was used, and cDNA synthesis, fragmentation and hybridizations were as described previously (Ren et al., 2004b; González Barrios et al., 2006a). Corroborating the deletion mutation, the microarray signals of the CP4-57 genes had very low signals. The gene expression data are accessible through GEO accession number GSE14472.

\section{Motility assay}

Cell motility was examined as described previously with low-salt (1\% tryptone, $0.25 \% \mathrm{NaCl}$ and $0.3 \%$ agar) (González Barrios et al., 2006b) and high-salt (1\% tryptone, $2.5 \% \mathrm{NaCl}$ and $0.3 \%$ agar) (Muramoto et al., 1995) media. Motility halos were quantified after $16 \mathrm{~h}$ using at least three plates for each condition and two independent cultures for each strain.

\section{Results}

Prophage genes affect E. coli physiology

To begin to discern the impact of prophage genes on $E$. coli physiology, we tested the effect of deleting each of the 40 genes of prophages, CP4-57 and DLP12, on biofilm formation. After $7 \mathrm{~h}$, deleting int $A$ (an integrase) of CP4-57 resulted in sixfold-less biofilm formation compared to the wild-type strain, whereas deleting the rest of the 17 genes increased biofilm formation by 2- to 12-fold (Figure 1a). Similar results were seen on deleting each DLP12 gene (Figure 1b). Hence, deleting many prophage genes affects biofilm formation in a complex manner.

Integrase overexpression leads to prophage excision Given their large impact on biofilm formation, we tested whether the cryptic prophages, CP4-57 and DLP12, remain excision proficient using a PCRbased assay. The excision of cryptic prophage from the chromosome, using a site-specific recombination event between the attL and attR sites, should generate an extrachromosomal phage-like circle and completely remove the phage from the chromosome (Sozhamannan et al., 2006). Primers flanking each prophage were designed to detect the presence of an empty site caused by prophage excision (Figure 2c shows CP4-57 primers, CP4-57f and CP4-57r). Due to the size of the prophage $(22 \mathrm{~kb})$ and the DNA amplification conditions, these primers do not amplify the intact region harboring prophage. After $12 \mathrm{~h}$, overexpressing integrase from CP4-57 (IntA) using plasmid pCA24N-int $A$ in an int $A$ host led to the excision and loss of this prophage from planktonic cells, and overexpression of integrase from DLP12 (IntD) using plasmid pCA24N-intD in an intD host led to the excision of DLP12 from planktonic cells as seen by clear PCR products with expected sizes (Table 2). PCR products from the chromosomal template were sequenced to confirm the loss of each prophage. In addition, overexpressing AlpA, a key transcriptional regulator of IntA, led to $\mathrm{CP} 4-57$ excision from planktonic cells. This result is in agreement with an earlier study (Kirby et al., 1994) in which AlpA expression increased IntA synthesis and led to the excision of this prophage. Overexpression via pCA24N of YpjF for CP4-57 and AppY, BorD, EssD, OmpT, RzpD and YbcS for DLP12 did not cause excision under these experimental conditions. The CP4-57 excision caused a loss of 22030 bp (Figure 2) from the host chromosome, and DLP12 caused a loss of $21302 \mathrm{bp}$. Therefore, both cryptic prophages retain the ability to excise from E. coli K-12. CP457 excision by AlpA and IntA overexpression was previously reported (Kirby et al., 1994; Trempy et al., 1994), but to our knowledge, this is the first report of DLP12 excision.

In addition, a quantification method (qPCR) using genomic DNA as templates was used to determine the fraction of cells that undergo excision upon overexpressing AlpA using primers CP4-57-2f and CP4-57-2r (Table 2), and upon overexpressing IntD using primers DLP12-2f and DLP12-2r (Table 2), which target each region devoid of prophage and by using the reference gene, purA, to quantify the number of all cells. In $12 \mathrm{~h}$, overexpressing AlpA causes $18-32 \%$ of the planktonic cells to excise and lose CP4-57, and overexpressing IntD causes 44$87 \%$ of the cells to excise DLP12. Hence, the cryptic prophages, CP4-57 and DLP12, remain excision proficient, and the overexpression of integrase and its transcriptional activator leads to a large proportion of cells to excise prophage.

\section{Prophage genes excise naturally in biofilms}

Through a temporal study (Domka et al., 2007), we found that AlpA was induced in biofilm cells but not in planktonic cells. Therefore, we tested whether prophage excision occurs naturally in the 

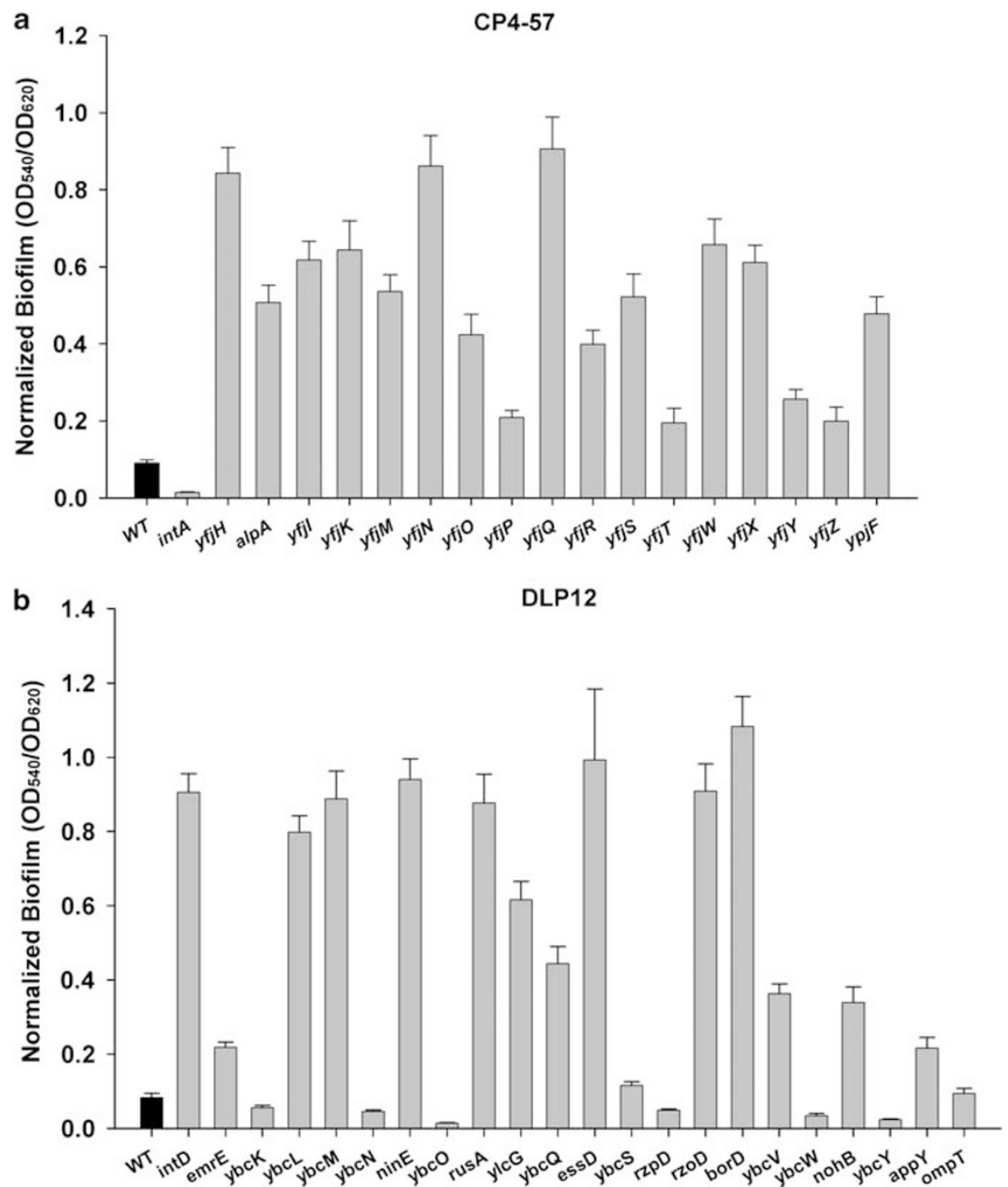

Figure 1 Biofilm formation of CP4-57 and DLP12 deletion mutants. Normalized biofilm formation (total biofilm/growth) after $7 \mathrm{~h}$ in Luria-Bertani (LB) medium at $37^{\circ} \mathrm{C}$ in 96-well polystyrene plates after the deletion of each CP4-57 gene (a) and each DLP12 gene (b). Data are the average of 10 replicate wells from two independent cultures, and one standard deviation is shown. Genes are listed in the order of their position on the Escherichia coli chromosome.

wild-type strain. Biofilm and planktonic cells were collected after $4,7,15,24,48$ and $72 \mathrm{~h}$ of incubation with $10 \mathrm{~g}$ glass wool. The fraction of cells that undergo excision was quantified by qPCR using genomic DNAs. The excision of CP4-57 was detected in biofilm cells from 4 to $72 \mathrm{~h}$, whereas for planktonic cells, excision was only found after a long time (24, 48 and $72 \mathrm{~h}$ ). The estimated fractions of cells undergoing CP4-57 excision were 1-2 per 10000 for both biofilm and planktonic cells at 48 and $72 \mathrm{~h}$. For DLP12, excision was consistently found from 4 to $72 \mathrm{~h}$ incubation times in both biofilm and planktonic cells. Hence, we discovered that the excision of CP4-57 and DLP12 occurs in the development of biofilms, and as CP4-57 is excised predominantly in biofilms at early stages, prophage excision may play a role in biofilm development.
Hha causes prophage excision

Earlier, we found that Hha is related to CP4-57 and DLP12, in that 8 CP4-57 genes and 10 DLP12 genes are differentially expressed in biofilms relative to planktonic cells for the hha mutant, and Hha also binds CP4-57 and DLP12 in vivo as well as to regions flanking these prophages (García-Contreras et al., 2008). Therefore we tested the role of Hha in prophage excision. In planktonic cells, Hha overexpression in an hha mutant using pCA24N-hha caused at least a 2048-fold increase in CP4-57 excision when compared with the hha strain with an empty vector in LB medium after $15 \mathrm{~h}$. The chromosome devoid of CP4-57 caused by Hha overexpression was present at low frequencies, ranging from 1 to 2 excisions per 10000 planktonic cells. Similar results were obtained in biofilm and planktonic cells in LB glu medium after $15 \mathrm{~h}$, 


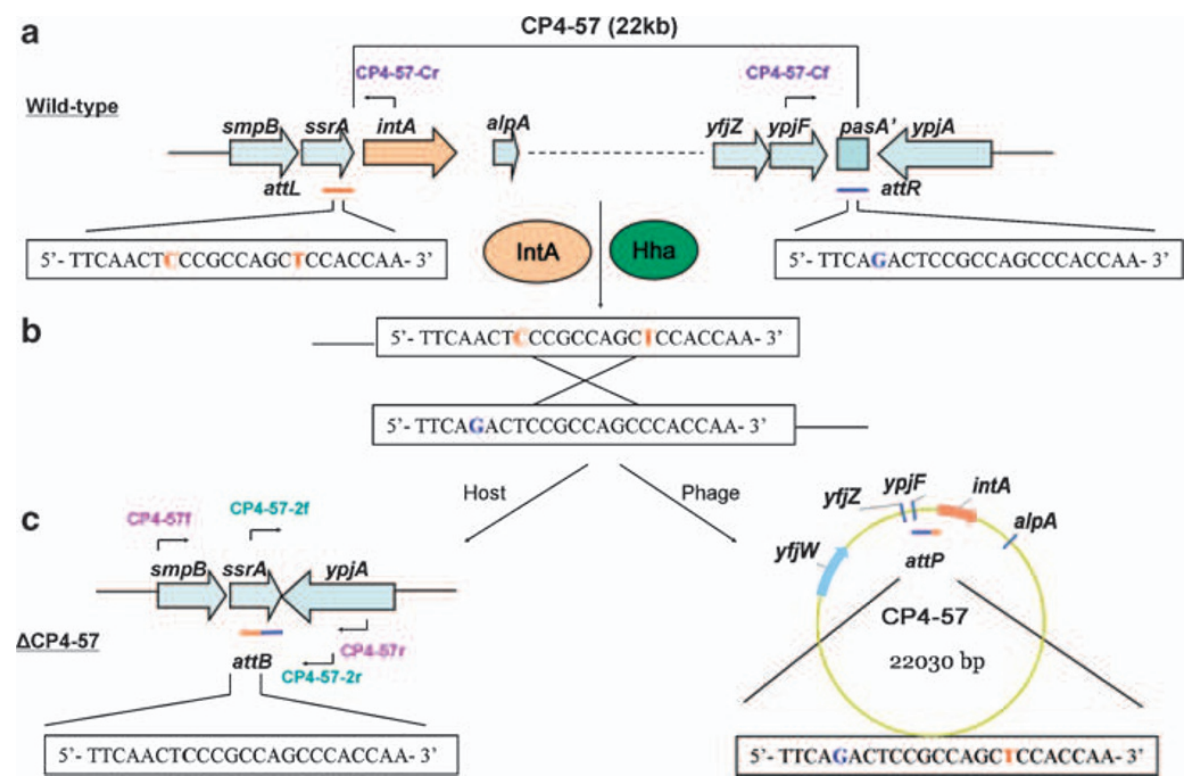

Figure 2 Schematic of CP4-57 excision. The position and unique sequences of the two attachment sites in the wild-type strain are indicated. The left-hand attachment site ( $a t t L)$ is an orange bar and the right-hand attachment site (attR) is a blue bar (a). During excision, a crossover occurs between these two att sites after the host protein, Hha, induces excision (b). After excision, a new strain, $\Delta \mathrm{CP} 4-57^{\text {circle }}$, is formed with CP4-57 removed from the chromosome and excised CP4-57 circularized to form a phage-like circle. The attB site is retained in the bacterium and $a t t P$ is retained in the phage-like circle (c). The position of the primers is indicated. To form a strain that completely lacks the CP4-57 prophage, named $\Delta \mathrm{CP} 4-57$, AlpA (alternative Lon protease), a transcriptional regulator of int $A$, whose overexpression is known to induce CP4-57 excision (Kirby et al., 1994), was overexpressed in an alpA deletion background with plasmid pCA24N-alpA using $1 \mathrm{mM}$ isopropyl- $\beta$-D-thiogalactopyranoside (IPTG) for $4 \mathrm{~h}$ during exponential growth to induce CP4-57 excision. Cells that underwent excision were screened by PCR for the presence of PCR products indicating the removal of the prophage. Upon removal of CP4-57, PCR using forward primer (CP4-57f) from the upstream gene, smpB, and reverse primer (CP4-57r) from the downstream gene (yрjA) generates a $1.2 \mathrm{~kb}$ excision-specific fragment (c). Genomic DNA was used as a template for PCR. Initially, we found that excised CP4-57 forms a phage circle by using a PCR-based assay, and this circle is retained in the cell, named $\Delta$ CP4-57 $7^{\text {circle }}$. Primers, CP4-57-Cf inside ypjF and CP4-57-Cr, inside int $A$ inside of CP4-57 facing outward on the chromosome (a) amplify a PCR product only when a DNA circle is formed at the attP site (c). The expected PCR product ( $850 \mathrm{bp}$ ) was obtained and was sequenced to confirm the circularization of CP4-57. To obtain $\triangle \mathrm{CP} 4-57$ that lacks the phage circle, cells were further cultured in Luria-Bertani (LB) medium for $24 \mathrm{~h}$ and screened for the loss of the kanamycin-resistance gene that replaced alpA inside CP4-57 (Baba et al., 2006). The kanamycin-sensitive strain was purified, then cultured in LB medium at $25^{\circ} \mathrm{C}$ for $24 \mathrm{~h}$ to remove pCA24N-alpA by screening for the loss of chloramphenicol resistance. The complete deletion of the CP4-57 prophage in $\Delta \mathrm{CP} 4-57$ was verified by PCR using primer sets, CP4-57f and CP4-57r (Table 2), by DNA sequencing (GenBank accession number FJ619521), as well as by the whole-transcriptome study of $\Delta$ CP4-57 vs the wild-type strain.

wherein we measured 1.5-1.9 excisions per 10000 cells. For DLP12, we measured 0.5-1.8 excisions per 10000 cells under the conditions of Hha overexpression described above for both biofilm and planktonic cells. Hence, Hha promotes CP4-57 and DLP12 excision. Corroborating the Hha overexpression results, there was no detectable CP4-57 or DLP12 excision in an hha deletion background for both biofilm and planktonic cells.

Deletion of Hha represses prophage gene expression qRT-PCR was performed first to test the effect of deleting hha on the expression of prophage genes that are related to excision in biofilm cells. Compared with the wild-type strain, deleting hha repressed the transcription of alp $A$ of CP4-57 $(-4.00 \pm 0.04$-fold), of int $A$ of CP4-57 $(-2.29 \pm 0.04$ fold) and of intD of DLP12 (-1.52 \pm 0.03 -fold), after $15 \mathrm{~h}$ of incubation in LB glu medium. These results indicate that the host protein, Hha, induces prophage-excision genes.
Excision of CP4-57 and SsrA

SsrA, also known as tmRNA or 10Sa RNA (Dulebohn et al., 2007), serves as an attachment site for CP4-57. It has been proposed that the use of attachment sites at the $3^{\prime}$-end of tRNAs or tmRNAs ensures the evolutionary stability of the phage (Hou, 1999). Therefore, we investigated whether CP4-57 excision causes a change in SsrA by comparing the sequences near the att site before and after CP4-57 excision. DNA sequencing showed that there is a one-base difference between the att site before prophage insertion (attB) (Figure 2c) and the att site after prophage insertion (attL) (Figure 2a). Hence, CP4-57 excision leads to a one-base change (deletion of a ' $T$ ') at the 3 '-end of the mature SsrA, in agreement with that which was predicted previously (Kirby et al., 1994). This indicates that a crossover occurs between attL and attR upon excision, as shown in Figure 2b (between position 8 and position 17 at $a t t L$ ). The additional base $\mathrm{T}$ at the $3^{\prime}$-end of SsrA was also found in E. coli strains that do not harbor CP4-57, including SMS-3-5, HS, 
IAI1 and W3110, as well as in Shigella boydii CDC 3083-94. These results indicate that CP4-57 excision causes a change in the $\operatorname{ssr} A$ gene.

We also tested whether the deletion of CP4-57 altered SsrA transcription, using qRT-PCR, and found that the transcription of SsrA in the $\triangle \mathrm{CP} 4$ 57 strain was similar to that of the wild-type strain in both biofilm cells (fold change $0.96 \pm 0.09$ ) and in planktonic cells (fold change $1.14 \pm 0.04$ ) after $7 \mathrm{~h}$ incubation in LB medium. In addition, a wholetranscriptome study (BW25113 $\Delta$ CP4-57 vs BW25113) using exponentially growing planktonic cells also showed that there was no change in SsrA transcription. Taken together, these results demonstrate that excision of the downstream prophage does not alter SsrA transcription even though the prophage utilizes SsrA for attachment.

Hha represses SsrA transcription, and SsrA is required for CP4-57 excision

Although not essential in E. coli, SsrA activity is essential for bacterial growth under adverse conditions because of its function in trans translation (Hong et al., 2007). We previously indicated that SsrA may be under the control of Hha, and both are involved in the activation of prophage and cell lysis (García-Contreras et al., 2008). Here, qRT-PCR using RNA samples extracted from biofilm cells after $15 \mathrm{~h}$ of incubation in LB glu medium showed that overexpressing Hha repressed SsrA transcription by $-3.0 \pm 0.5$-fold. This result is consistent with our earlier whole-transcriptome analysis, under the same experimental conditions, wherein SsrA transcription was repressed by -3.9 -fold (GarcíaContreras et al., 2008). Corroborating this result, qRT-PCR using RNA samples from the hha deletion isogenic mutant and from the wild-type strain also showed that $s s r A$ transcription is induced $(2.1 \pm 0.1$ fold) upon deleting hha. Taken together, these three independent results show tha negatively regulates ssrA transcription.

The transcribed region of SsrA overlaps with the CP4-57 prophage genes, in that the $3^{\prime}$-end of the mature ssrA transcript includes the attachment CP457 site (attL) (Figure 2). To study the effect of SsrA on CP4-57, we constructed two ssrA deletion mutants in which the promoter and the entire or a part of the mature transcript of SsrA were deleted from the chromosome of BW25113. Mutant ssrA no longer has an attL site, whereas mutant $\operatorname{ssr} A$ att $L^{+}$ retains an intact attL site. When AlpA was overexpressed by plasmid pCA24N in the $s s r A$ deletion strain, due to the absence of attL required for excision, no CP4-57 excision was detected by qPCR in LB medium after $15 \mathrm{~h}$. Moreover, in the SsrA deletion mutant that contains the attL site (ssrA $a t t L^{+}$), CP4-57 excision was not detected by qPCR when AlpA was overexpressed in LB medium after $15 \mathrm{~h}$ that leads to an at least 70000 -fold repression of excision. Therefore, both functional SsrA and its
attL site are necessary for CP4-57 excision, and the role of SsrA in CP4-57 excision is more than serving as an attachment site, but the exact role of SsrA in the Hha induction of CP4-57 excision remains to be fully elucidated.

The effect of Hha and SsrA on biofilm was also investigated. The deletion of Hha increased early biofilm formation by $7 \pm 1$-fold, whereas the partial deletion of SsrA (ssrA attL $L^{+}$) decreased early biofilm formation by $2.1 \pm 0.1$-fold at $7 \mathrm{~h}$ in LB medium. Moreover, the deletion of both Hha and SsrA decreased early biofilm formation by the same amount as that by the deletion of SsrA. Therefore, deletion of host factors that control prophage excision affect biofilm formation at early stages in a complex manner. As expected, we also found that the strain, ssrA attL $L^{+}$, was more sensitive to the toxicity caused by overexpressing Hha, as SsrA is required for growth under stressful conditions (Hong et al., 2007).

\section{Deletion of complete CP4-57 reduces cell growth} To study the effect of CP4-57 on E. coli gene expression and physiology, we constructed a new isogenic strain, BW25113 $\Delta \mathrm{CP} 4-57$, in which the whole prophage $(22030 \mathrm{bp})$ was removed (including the excised phage circle) in a way that is equivalent to natural excision (Figure 2). To study the effects of the removal of CP4-57 on host fitness, we tested the growth of $\Delta \mathrm{CP} 4-57$ in different media. Compared with the isogenic wild-type strain, $\Delta$ CP4-57 grew more slowly in both nutrient-rich and nutrient-poor media. The specific growth rate $\left(\mathrm{h}^{-1}\right)$ was $1.40 \pm 0.01$ vs $1.67 \pm 0.01$ in LB (Figure $3 \mathrm{a}$ ) and $1.51 \pm 0.01$ vs $1.71 \pm 0.02$ in LB glu (Figure $3 b$ ) for $\Delta C P 4-57$ and the wild-type strain, respectively. Even larger differences in the specific growth rate were observed between these two strains in minimal medium; the specific growth rate $\left(\mathrm{h}^{-1}\right)$ was $0.24 \pm 0.01$ vs $0.70 \pm 0.01$ in M9 minimal medium (M9C) (Figure 3c) and $0.27 \pm 0.06$ vs $0.93 \pm 0.02$ in M9C with $0.1 \%$ lactate (M9C lactate) (Figure 3d) for $\Delta \mathrm{CP} 4-57$ and the wild-type strain, respectively. Hence, growth inhibition in $\triangle \mathrm{CP} 4-57$ was shown in a nutrient-dependent manner, indicating an active and beneficial role of prophage in host physiology especially in nutrient-poor conditions.

\section{Removal of CP4-57 affects biofilm formation}

As with deleting each gene of CP4-57 (Figure 1), deleting all of CP4-57 affected biofilm formation. Deleting CP4-57 increased early biofilm formation up to $4.6 \pm 0.2$-fold at $7 \mathrm{~h}$ and increased dispersal as there was a $2.3 \pm 0.1$-fold-less biofilm at later stages $(33 \mathrm{~h})$ in 96-well polystyrene plates (Figure 4a). Corroborating these results, the total number of viable cells in the biofilm formed on polystyrene tubes increased slightly for $\Delta \mathrm{CP} 4-57$ at early stages (1.7 \pm 0.2 -fold after $15 \mathrm{~h}$, Figure $4 \mathrm{~b})$ and decreased at 

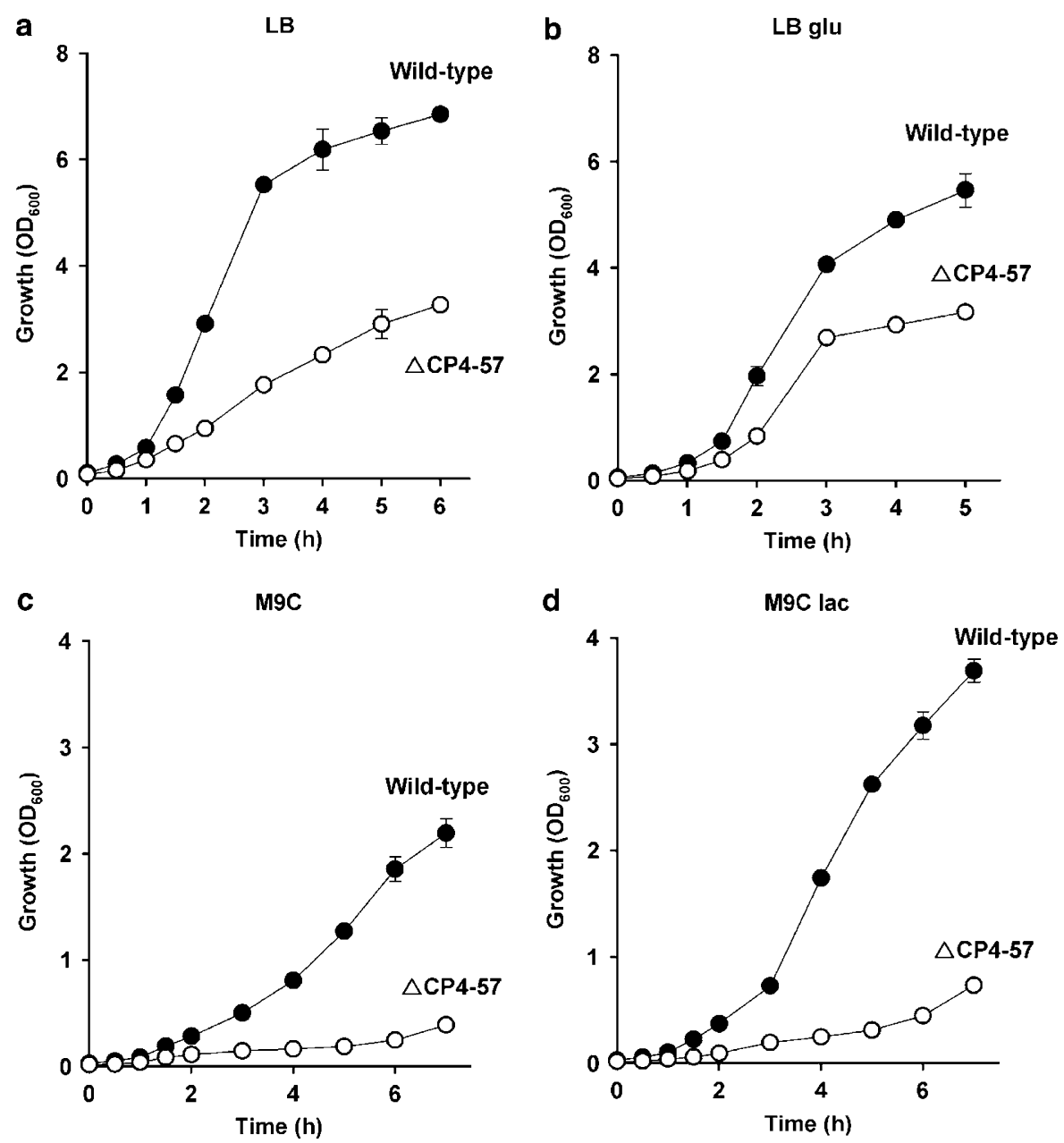

Figure 3 Growth of $\Delta$ CP4-57 in different media. Growth in Luria-Bertani (LB) (a), LB containing 0.2\% glucose (LB glu) (b), M9 minimal medium with $0.2 \%$ casamino acids (M9C) (c) and M9C with $0.1 \%$ lactate (M9C lactate) (d) media, at $37^{\circ} \mathrm{C}$. Data are from two independent cultures, and one standard deviation is shown.

later stages (2.8 \pm 0.3 -fold after $36 \mathrm{~h}$, Figure $4 \mathrm{~b})$. For the planktonic cells of both the wild-type strain and $\Delta \mathrm{CP} 4-57$, there was no significant change in turbidity after $40 \mathrm{~h}$ of incubation and no change in the number of viable cells; hence, there was no apparent cell lysis or change in growth that led to these differences in biofilm formation. Therefore, prophage CP4-57 affects biofilm formations in a temporal manner, and the genes of CP4-57 primarily serve to reduce early biofilm formation.

Deleting CP4-57 induces motility through flagella and represses carbohydrate metabolism

A whole-transcriptome study was performed to characterize the effect of removing CP4-57 from $E$. coli and to explore the effects of CP4-57 on host physiology at the transcriptional level. In exponentially growing planktonic wild-type cells, 25 prophage genes had signals higher than 500, the average signal (Supplementary Table S1). Hence, prophage genes actively participate in host physiology even in planktonic cells.
Upon deleting the CP4-57 prophage, 36 flagellarelated genes were induced, and these were the most upregulated genes (Table 3). Flagella affects cell motility, which is critical for early attachment for biofilm development (Pratt and Kolter, 1998), and it affects mature biofilm architecture in E. coli (Wood et al., 2006). Corroborating this increase in transcription of the flagellar loci, motility assays showed clearly that deletion of CP4-57 induced motility $8 \pm 1$-fold (halo diameter for $\Delta \mathrm{CP} 4-57$ is $5.8 \pm 0.6 \mathrm{~cm}$ ) compared with that of the wild-type strain (halo diameter for wild type is $0.8 \pm 0.1 \mathrm{~cm}$ ) on a low-salt motility agar plate (Figure 5a). Furthermore, the wild-type strain did not show any motility in highsalt motility plates, whereas $\Delta \mathrm{CP} 4-57$ formed halos (Figure 5b). Salt concentrations $(\mathrm{NaCl})$ affect cell motility by affecting the rotation rate of the flagella motor (Muramoto et al., 1995). This result provides another line of evidence that CP4-57 prophage is involved in the development of biofilms through flagella synthesis and rotation.

The loss of CP4-57 repressed a group of genes involved in carbohydrate metabolism (for example, 

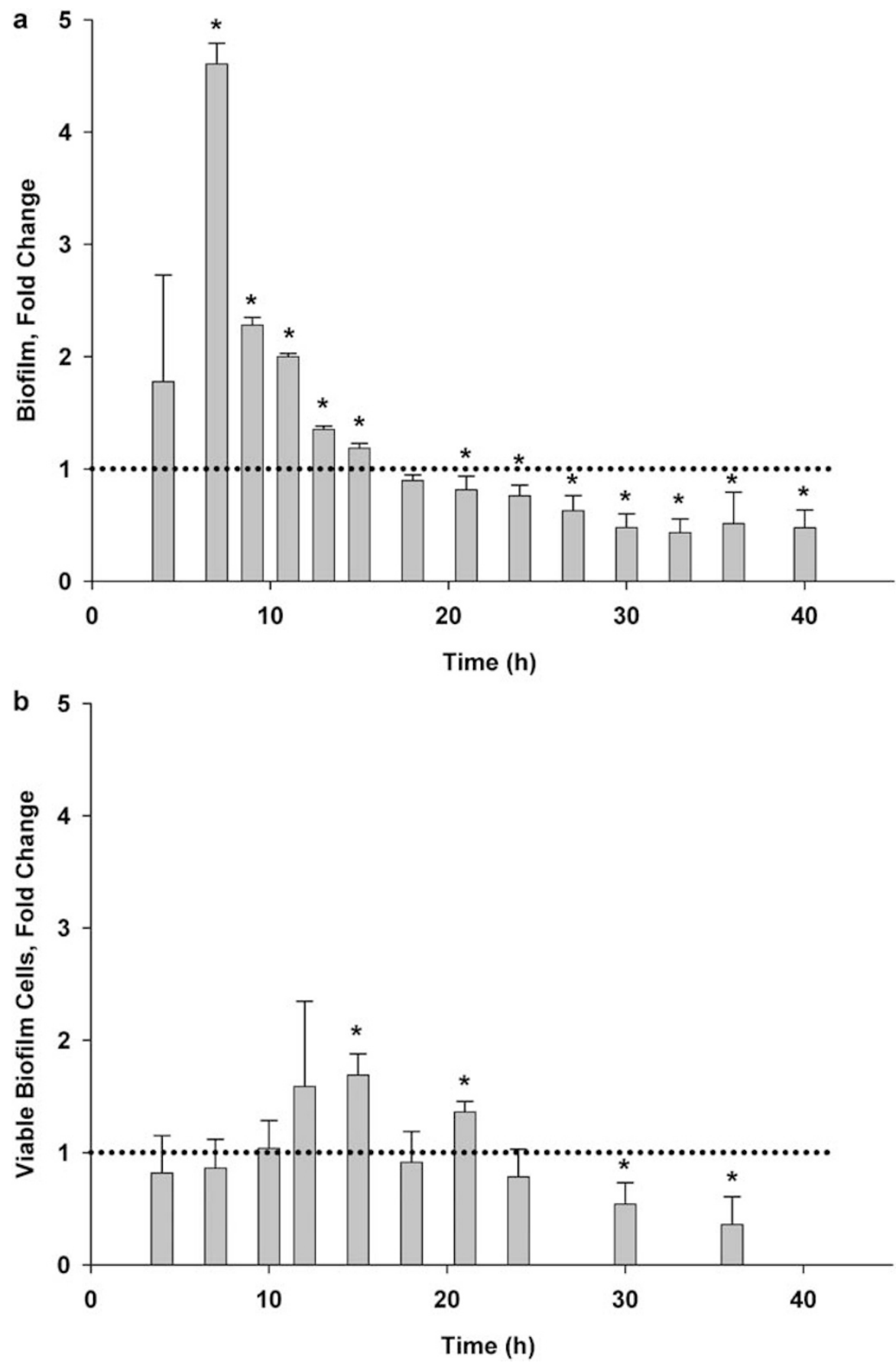

Figure 4 Biofilm formation of $\Delta$ CP4-57. (a) The fold change in normalized biofilm formation in 96-well polystyrene plates in LuriaBertani (LB) medium at $37^{\circ} \mathrm{C}$ was determined for $\Delta \mathrm{CP} 4-57$ vs for the wild-type strain. Data are the average of 12 replicate wells from four independent cultures, and one standard deviation is shown. (b) Fold change for the total number of viable biofilm cells (CFU per ml) in $14 \mathrm{ml}$ polystyrene tubes in LB medium at $37^{\circ} \mathrm{C}$ was determined for $\Delta \mathrm{CP} 4-57$ vs for the wild-type strain. Data are the average of two replicate tubes from two independent cultures, and one standard deviation is shown. Time point when $P<0.05$ (Student's $t$-test) is marked with asterisk.

lldPRD, sdhCDAB, sucABCD and aceAB), and amino-acid metabolism (for example, $\operatorname{dad} A X$, putAP, tnaBL and trpAB) (Table 3). Succinyl-CoA synthetase (encoded by sucABCD), succinate dehydrogenase (encoded by $s d h A B C D$ ) and malate synthetase (encoded by aceB) are key enzymes in the tricarboxylic acid (TCA) cycle, and a repression of the TCA cycle reduces energy production. These results could explain the reduced growth rate of $\Delta$ CP4-57 in different media (Figure 3). In addition, $I l d P$ and $l l d R$, encoding for a lactate utilization system, were also two of the three genes found most differentially expressed in a lambda lysogen vs nonlysogenic E. coli (Osterhout et al., 2007), although the changes were relatively small. The loss of CP4-57 also affected the two terminal 
Table 3 List of differentially expressed genes in exponentially grown, planktonic cells of BW25113 $\Delta$ CP4-57 vs wild-type strain in LB medium at $37^{\circ} \mathrm{C}$

Group and gene b number $\begin{gathered}\text { Fold } \\ \text { change }\end{gathered}$ Description

\begin{tabular}{|c|c|c|c|}
\hline \multicolumn{4}{|c|}{ Flagella related } \\
\hline$f \lg A$ & b1072 & 2.5 & Assembly of basal-body periplasmic $P$ ring \\
\hline flg $B$ & b1073 & 2.5 & Cell-proximal portion of basal-body rod \\
\hline$f \lg C$ & b1074 & 2.6 & Cell-proximal portion of basal-body rod \\
\hline flg $D$ & b1075 & 2.6 & Initiation of hook assembly \\
\hline flgE & b1076 & 2.1 & Hook protein \\
\hline flgF & b1077 & 3.7 & Cell-proximal portion of basal-body rod \\
\hline flgG & b1078 & 2.5 & Cell-distal portion of basal-body rod \\
\hline flg & b1079 & 2.1 & Membrane L (lipopolysaccharide layer) ring protein \\
\hline flgI & b1080 & 2.0 & Basal body P-ring flagellar protein \\
\hline flgJ & b1081 & 2.0 & Motor activity \\
\hline flgK & b1082 & 2.0 & Motor activity \\
\hline flg $L$ & b1083 & 1.6 & Hook-filament junction protein \\
\hline flgM & b1071 & 2.0 & Anti-sigma 28 (FliA) factor, regulator of FlhD \\
\hline flgN & b1070 & 1.9 & Initiation of flagellar filament assembly \\
\hline flhA & b1879 & 1.6 & Possible export of flagellar proteins \\
\hline flhB & b1880 & 1.9 & Putative part of export apparatus for flagellar proteins \\
\hline flhC & b1891 & 1.7 & Flagellar transcriptional activator \\
\hline flhD & b1892 & 1.9 & Flagellar transcriptional activator \\
\hline flhE & b1878 & 1.5 & Function unknown \\
\hline fliA & b1922 & 3.0 & Regulation of flagellar operons \\
\hline flic & b1923 & 1.6 & Flagellin, filament structural protein \\
\hline fliD & b1924 & 1.5 & Filament capping protein, enables filament assembly \\
\hline fliE & b1937 & 2.3 & Basal-body component, possibly at (MS-ring)-rod junction \\
\hline fliF & b1938 & 2.5 & Basal-body component \\
\hline fliG & b1939 & 2.3 & Rotor protein for flagellar motor switching and energizing \\
\hline fliH & b1940 & 2.3 & Negative regulator of FliI ATPase activity \\
\hline fliI & b1941 & 2.1 & Flagellum-specific ATP synthase \\
\hline flij & b1942 & 2.1 & Flagellin export apparatus soluble chaperone \\
\hline fliK & b1943 & 1.9 & Flagellar hook-length control protein \\
\hline fliL & b1944 & 2.5 & Affects rotational direction of flagella during chemotaxis \\
\hline fliM & b1945 & 2.5 & Switch and energizing, enabling rotation and determining its direction \\
\hline fliN & b1946 & 2.5 & Switch and energizing, enabling rotation and determining its direction \\
\hline fliO & b1947 & 1.9 & Flagellum organization and biogenesis \\
\hline fliP & b1948 & 1.7 & Protein secretion \\
\hline fliQ & b1949 & 1.6 & Protein secretion \\
\hline fli $\tilde{Z}$ & b1921 & 2.8 & DNA integration \\
\hline \multicolumn{4}{|c|}{ Small RNA } \\
\hline$r y d B$ & b4430 & 2.1 & Novel sRNA, function unknown \\
\hline \multicolumn{4}{|c|}{ Electron transport } \\
\hline cydA & b0733 & 1.9 & Cytochrome $d$ terminal oxidase subunit I \\
\hline cydB & b0734 & 1.9 & Cytochrome $d$ terminal oxidase subunit II \\
\hline СуоB & b0431 & -1.6 & Cytochrome $o$ ubiquinol oxidase subunit I \\
\hline суо C & b0430 & -1.7 & Cytochrome $o$ ubiquinol oxidase subunit III \\
\hline CyoD & b0429 & -1.7 & Cytochrome $o$ ubiquinol oxidase subunit IV \\
\hline СУоE & b0428 & -1.6 & Protoheme IX farnesyltransferase \\
\hline betA & b0311 & -1.7 & Choline dehydrogenase \\
\hline betB & b0312 & -1.7 & Betaine aldehyde dehydrogenase, NAD dependent \\
\hline betI & b0313 & -1.5 & Choline sensing \\
\hline \multicolumn{4}{|c|}{ Amino-acid metabolism } \\
\hline$t d c A$ & b3118 & 1.9 & Transcription activator of threonine dehydratase \\
\hline$t d c B$ & b3117 & 1.9 & Threonine dehydratase \\
\hline$t d c C$ & b3116 & 1.5 & Threonine dehydratase \\
\hline $\operatorname{dad} A$ & b1189 & -2.1 & D-amino acid dehydrogenase subunit \\
\hline dadX & b1190 & -2.5 & Alanine racemase 2 , catabolic \\
\hline putA & b1014 & -2.3 & Proline dehydrogenase, P5C dehydrogenase \\
\hline putP & b1015 & -2.8 & Major sodium/proline symporter \\
\hline $\operatorname{tn} a B$ & b3709 & -1.5 & Low-affinity tryptophan permease \\
\hline tnaL & b3707 & -1.5 & Tryptophanase leader peptide \\
\hline $\operatorname{trp} A$ & b1260 & -1.6 & Tryptophan synthase, $\alpha$-protein \\
\hline $\operatorname{trp} B$ & b1261 & -1.6 & Tryptophan synthase, $\beta$-protein \\
\hline
\end{tabular}


Table 3 Continued

\begin{tabular}{|c|c|c|c|}
\hline Group and gene & b number & $\begin{array}{c}\text { Fold } \\
\text { change }\end{array}$ & Description \\
\hline \multicolumn{4}{|c|}{ Carbohydrate metabolism } \\
\hline $\operatorname{lldP}$ & b3603 & -3.0 & L-lactate permease \\
\hline$l l d R$ & b3604 & -2.5 & Transcriptional regulator \\
\hline $\operatorname{lld} D$ & b3605 & -2.3 & L-lactate dehydrogenase \\
\hline $\operatorname{sdh} A$ & b0723 & -1.9 & Succinate dehydrogenase, flavoprotein subunit \\
\hline$s d h B$ & b0724 & -1.9 & Succinate dehydrogenase, iron sulfur protein \\
\hline$s d h C$ & b0721 & -1.7 & Succinate dehydrogenase, cytochrome b556 \\
\hline$s d h D$ & b0722 & -1.7 & Succinate dehydrogenase, hydrophobic subunit \\
\hline sucA & b0726 & -1.9 & Succinate dehydrogenase (decarboxylase component) \\
\hline sucB & b0727 & -1.6 & Dihydrolipoamide succinyltransferase component of 2-oxoglutarate dehydrogenase complex \\
\hline sucC & b0728 & -1.9 & Succinyl-CoA synthetase, $\beta$-subunit \\
\hline sucD & b0729 & -1.7 & Succinyl-CoA synthetase, $\alpha$-subunit \\
\hline aсе $A$ & b4015 & -1.7 & Isocitrate lyase \\
\hline ace $B$ & b4014 & -1.5 & Malate synthetase A \\
\hline$m g l A$ & b2149 & -1.6 & Alactoside transport and galactose taxis \\
\hline $\mathrm{mglC}$ & b2148 & -1.7 & Alactoside transport and galactose taxis \\
\hline glt $A$ & b0720 & -2.1 & Citrate synthetase \\
\hline fumA & b1612 & -1.6 & Fumarate hydratase class I \\
\hline fumC & b1611 & -1.7 & SoxRS regulon, fumarate hydratase class II \\
\hline acs & b4069 & -1.7 & Acetyl-CoA synthetase \\
\hline $\operatorname{ald} A$ & b1415 & -1.7 & Aldehyde dehydrogenase, NAD linked \\
\hline maeB & b2463 & -1.9 & NADP-dependent malic enzyme; NADP-ME \\
\hline \multicolumn{4}{|l|}{ Unknown } \\
\hline yecR & b1904 & 1.9 & Function unknown \\
\hline$y d c I$ & b1422 & -1.7 & Function unknown \\
\hline
\end{tabular}
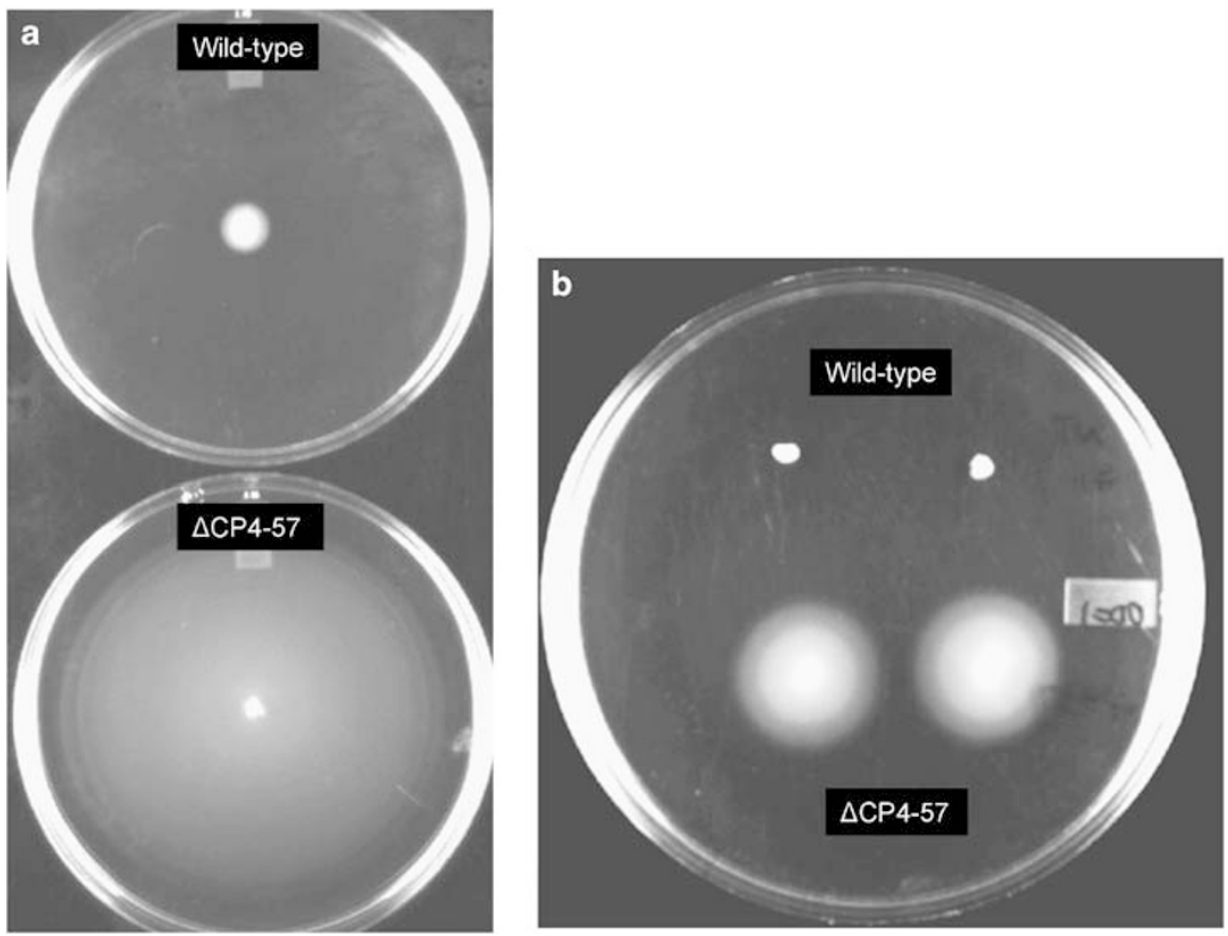

Figure 5 Motility of $\Delta \mathrm{CP} 4-57$. Swimming motility of $\Delta \mathrm{CP} 4-57$ in low-salt motility agar plates (a) and high-salt motility agar plates (b). One microliter of overnight culture was inoculated onto motility agar plates that were photographed after incubation for $16 \mathrm{~h}$ at $37^{\circ} \mathrm{C}$. Two independent cultures were used and only image is shown in panel a.

oxidases for the E. coli respiratory chain by activating genes involved in cytochrome $d$ terminal oxidase $c y d A B$ (Table 3 ) and by repressing genes involved in cytochrome $o$ terminal oxidase $c y o B C D E$
(Table 3); these changes are usually associated with anaerobic growth (Iuchi et al., 1990). Growth in minimal medium M9C with lactate (Figure 3d) and without lactate (Figure 3c) showed that $\Delta \mathrm{CP} 4-57$ 

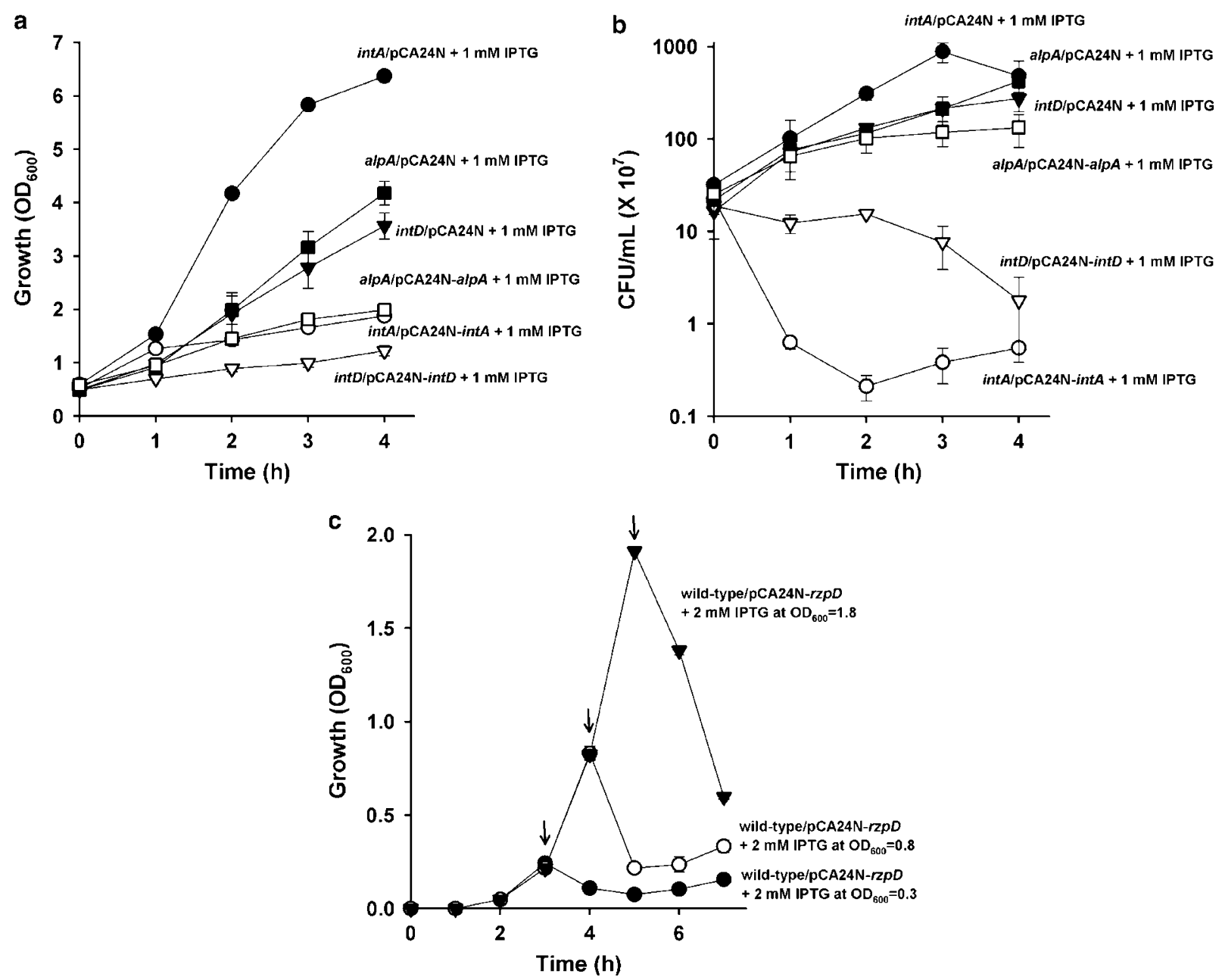

Figure 6 Toxicity of prophage genes. Growth (a) and cell viability (CFU per ml) (b) after overexpressing IntA, AlpA and IntD by pCA24N-int A, pCA24N-alpA and pCA24N-intD in Luria-Bertani (LB) medium with $1 \mathrm{mM}$ isopropyl- $\beta$ - $D$-thiogalactopyranoside (IPTG) at a turbidity of 0.5 at $600 \mathrm{~nm}$. Empty pCA24N vector of each strain with $1 \mathrm{mM}$ IPTG served as a negative control. Growth for overexpression of RzpD by adding $2 \mathrm{mM}$ IPTG at a turbidity of $0.3,0.5$ and 1.8 at $600 \mathrm{~nm}$ (c). Arrows indicate the time points for adding $2 \mathrm{mM}$ IPTG. Data are from two independent cultures, and one standard deviation is shown.

was unable to utilize lactate as well as the wild-type strain. The specific growth rate increased from $0.70 \pm 0.01$ to $0.93 \pm 0.02$ with the addition of $0.1 \%$ lactate for the wild type, whereas for $\Delta \mathrm{CP} 4-57$, growth did not change appreciably $(0.24 \pm 0.01$ vs $0.27 \pm 0.06$ ). Hence, the lactate utilization system seems to play an important role in host-phage interactions for both CP4-57 and lambda. Overall, the whole-transcriptome analysis showed that the loss of CP4-57 affected genes involved in metabolism and biofilm formation, especially motility, indicating that CP4-57, although defective, is still involved in host physiology and affects biofilm formation.

\section{Excised CP4-57 circularizes}

The excised CP4-57 prophage was found to form a circle, as confirmed by a PCR-based assay, followed by sequencing (Figure 2). In addition, there was an indication that the prophage genes were expressed while being a part of this phage circle after excision, as kanamycin resistance encoded within CP4-57 (alpA gene) was retained in the cell, which is distinct from the $\triangle \mathrm{CP} 4-57$ strain that does not have circularized CP4-57; hence, we named this strain $\Delta$ CP4-57 $7^{\text {circle }}$ (Table 2). However, in agreement with that which has been reported previously (Kirby et al., 1994), the circularized prophage was not maintained in the manner of a stable plasmid, probably due to the loss of its ability to complete a full phage replication cycle once excised from the host (Casjens, 2003), as, after $24 \mathrm{~h}$ of growth in fresh LB medium, more than $90 \%$ of the cells no longer had the phage circle.

Overexpression of IntA, IntD, AlpA and RzpD leads to cell death and lysis

IntA of CP4-57 and IntD of DLP12 remain functional as integrases, as shown by their ability to cause prophage excision as described earlier in this study. 
To explore whether these integrases are involved in cell death, we determined growth and cell viability by overexpressing IntA and IntD as well as AlpA (transcriptional activator for IntA). Growth and cell viability were significantly repressed after induction of int $A$ and intD, and a slight decrease was seen for $\operatorname{alp} A$ (Figures 6a and b). Moreover, the overexpression of $r z p D$ (a putative murein endopeptidase of DLP12) dramatically induced cell lysis (Figure 6c). Therefore, IntA, IntD, AlpA and RzpD are capable of causing cell death and cell lysis.

\section{Discussion}

Although prophages are abundant and widespread in bacteria, their roles in host physiology remain largely unexplored. We present the following lines of evidence to show that CP4-57 affects host E. coli physiology: (1) deleting each prophage gene and deleting all of CP4-57 affect biofilm formation in a temporal manner (Figures 1a, 4a and b); (2) prophage genes are actively expressed in exponentially growing planktonic cells, as shown by a whole-transcriptome study (Supplementary Table S1); (3) deleting CP4-57 decreases the specific growth rate and final cell density, especially in minimal medium (Figure 3); (4) deleting CP4-57 dramatically increases cell motility (Figure 5) as corroborated by induction of 36 flagella genes (Table 3); and (5) overexpression of prophage genes (IntA and AlpA) causes cell death (Figure 6). Taken together, these results show clearly that CP4-57 prophage participates in E. coli physiology including biofilm development.

Here we also show that prophage excision is a natural process during E. coli biofilm development. CP4-57 and DLP12 remain excision proficient, and the overexpression of integrase (IntA and IntD) as well as the activator of integrase (AlpA) leads to a large fraction of cells (18-87\%) that undergo excision. A low fraction of cells (around the order of 1 per 10000 ) undergo excision of CP4-57 and DLP12 in wild-type biofilms, and at early developmental stages (4-15 h), the excision of CP4-57 was only detected in biofilm cells but not in planktonic cells. This is consistent with our earlier study (Domka et al., 2007) that during the development of E. coli biofilms, AlpA is induced consistently from 4 to $24 \mathrm{~h}$ up to 11 -fold ( 24 vs $15 \mathrm{~h}$ ), and this induction should lead to CP4-57 excision.

We conclude from this study that the process of prophage excision is beneficial to E. coli biofilm development, at least for prophage CP4-57. The short-term growth of $P$. aeruginosa in biofilms generated extensive genetic diversity through a rec $A$-dependent recombination inside the community, and this self-generated diversity produces 'insurance effects' to increase the ability of cells to withstand various environmental stresses (Boles et al., 2004). The excision of CP4-57 from E. coli leads to the formation of a prophage-deficient strain and a phage-like circle that expresses some functional phage genes. The resulting prophage-deficient strain was shown to process specialized functions in biofilms, including enhanced motility, reduced growth and increased biofilm dispersal. Flagella motility plays an important role for early attachment to various surfaces (Pratt and Kolter, 1998) as well as in dispersal (Wood et al., 2006). Here we show that as early as at $4 \mathrm{~h}, \mathrm{CP} 4-57$ excision occurs only in biofilm cells of the wild-type strain. When CP4-57 is removed, swimming motility increases through induction of flagella synthesis, and this result is consistent with the observation that $\Delta \mathrm{CP} 4-57$ formed biofilm more quickly than did the wild-type strain at early stages, and is consistent with the increased dispersal (Figures 4a and b). This also provides an advantage, at least in part, for a wild-type strain to undergo prophage excision during the development of E. coli biofilms. The influence of CP4-57 on motility is a novel role for prophage. Moreover, the small proportion of cells that undergo prophage excision helps to reduce the overall requirement of nutrients by generating slow-growing cells (for example, $\Delta \mathrm{CP} 4-57$ ) or by killing a fraction of cells through the expression of prophage genes (for example, $\operatorname{alp} A$ and int $A$ ). Hence, for $E$. coli, prophage excision is involved in the population diversification inside the biofilm community, which has gained recognition as an important component in other bacteria, including $P$. aeruginosa (Webb et al., 2003b; Boles et al., 2004; Rice et al., 2009). One could imagine circumstances in which the presence of bacteria with differing motilities or divergent nutritional requirements would have advantages in the face of the adverse conditions faced in biofilms (Boles et al., 2004). It seems that $\Delta \mathrm{CP} 4-57$ displays a behavioral strategy that can enhance fitness in social groups despite being costly to itself in terms of growth (Crespi, 2001; Velicer and $\mathrm{Yu}, 2003)$.

The DNA-binding protein, Hha, is related to prophage gene expression, as we reported previously (García-Contreras et al., 2008), and Hha is a global regulator that has an important function in regulating horizontally transferred elements including pathogenicity islands (Vivero et al., 2008). Hha has been related to cell death by its binding to rare codon tRNAs to inhibit translation and by activating proteases (Lon, ClpP and ClpX) (García-Contreras et al., 2008). We show here that Hha promotes prophage excision directly by activating prophage genes. The lines of evidence that indicate Hha promotes excision are the following: (1) Hha induces the expression of int $A$ and alp $A$, which are known to induce excision and lead to cell death and (2) Hha causes prophage excision (shown by overexpressing Hha and deleting hha). Moreover, Hha repressed the trans-translation process by repressing SsrA, which facilitates the release of stalled ribosomes from damaged mRNAs and 
targets the aberrant protein for degradation (Hong et al., 2007). In this study, we found that Hha represses the transcription of SsrA, which in turn enhances the toxicity of Hha and which indicates that Hha and SsrA are intertwined as they regulate cell death.

Comparing $\Delta \mathrm{CP} 4-57$ with wild-type strains shows clearly that a complex coevolution event has occurred between the host and the phage for the wild-type strain. A whole-transcriptome study shows that one of the single most important phenotypes for biofilms, flagella synthesis, is induced and the most important metabolic pathway, the TCA cycle, is repressed when CP4-57 is removed. Both actions affect cell physiology and use many genes across the $E$. coli genome. In addition, the slow growth and increased motility of $\Delta \mathrm{CP} 4-57$ could be a trade-off under energetically limiting conditions during the coevolution of chromosomal genes (Pfeiffer et al., 2001) because both cell growth and flagella biogenesis/rotation are energetically costly (Tian et al., 2008). Since Hha induces expression of prophage genes and promotes excision, prophages have become a part of the regulatory circuitry of the $E$. coli host. We hypothesize that E. coli takes control of prophage and its excision, and uses these foreign genes to benefit itself for the biofilm mode of life.

\section{Acknowledgements}

This work was supported by the NIH (R01 EB003872) and by the ARO (W911NF-06-1-0408). We acknowledge the Genome Analysis Project in Japan for providing the Keio and ASKA strains.

\section{References}

Baba T, Ara T, Hasegawa M, Takai Y, Okumura Y, Baba M et al (2006). Construction of Escherichia coli K-12 inframe, single-gene knockout mutants: the Keio collection. Mol Syst Biol 2: 0008.

Bayles KW. (2003). Are the molecular strategies that control apoptosis conserved in bacteria? Trends Microbiol 11: 306-311.

Blattner FR, Plunkett III G, Bloch CA, Perna NT, Burland $\mathrm{V}$, Riley $\mathrm{M}$ et al (1997). The complete genome sequence of Escherichia coli K-12. Science 277: 1453-1462.

Boles BR, Thoendel M, Singh PK. (2004). Self-generated diversity produces 'insurance effects' in biofilm communities. Proc Natl Acad Sci USA 101: 16630-16635.

Boyd EF, Brüssow H. (2002). Common themes among bacteriophage-encoded virulence factors and diversity among the bacteriophages involved. Trends Microbiol 10: 521-529.

Canchaya C, Proux C, Fournous G, Bruttin A, Brussow H. (2003). Prophage genomics. Microbiol Mol Biol Rev 67: 238-276.
Carmona M, Balsalobre C, Muñoa F, Mouriño M, Jubete Y, De la Cruz F et al (1993). Escherichia coli hha mutants, DNA supercoiling and expression of the haemolysin genes from the recombinant plasmid pANN202-312. Mol Microbiol 9: 1011-1018.

Casjens S. (2003). Prophages and bacterial genomics: what have we learned so far? Mol Microbiol 49: 277-300.

Chen Y, Golding I, Sawai S, Guo L, Cox EC. (2005). Population fitness and the regulation of Escherichia coli genes by bacterial viruses. PLoS Biol 3: e229.

Cho EH, Gumport RI, Gardner JF. (2002). Interactions between integrase and excisionase in the phage lambda excisive nucleoprotein complex. J Bacteriol 184: 5200-5203.

Christensen SK, Gerdes K. (2003). RelE toxins from bacteria and archaea cleave mRNAs on translating ribosomes, which are rescued by tmRNA. Mol Microbiol 48: 1389-1400.

Crespi BJ. (2001). The evolution of social behavior in microorganisms. Trends Ecol Evol 16: 178-183.

de Mello Varani A, Souza RC, Nakaya HI, de Lima WC, Paula de Almeida LG, Kitajima EW et al (2008). Origins of the Xylella fastidiosa prophage-like regions and their impact in genome differentiation. PLOS ONE 3: e4059.

Domka J, Lee J, Wood TK. (2006). YliH (BssR) and YceP (BssS) regulate Escherichia coli K-12 biofilm formation by influencing cell signaling. Appl Environ Microbiol 72: 2449-2459.

Domka J, Lee J, Wood TK. (2007). Temporal geneexpression in Escherichia coli K-12 biofilms. Environ Microbiol 9: 322-346.

Donegan K, Matyac C, Seidler R, Porteous A. (1991). Evaluation of methods for sampling, recovery, and enumeration of cacteria applied to the phylloplane. Appl Environ Microbiol 57: 51-56.

Dulebohn D, Choy J, Sundermeier T, Okan N, Karzai AW. (2007). Trans-translation: the tmRNA-mediated surveillance mechanism for ribosome rescue, directed protein degradation, and nonstop mRNA decay. Biochemistry 46: 4681-4693.

García-Contreras R, Zhang X-S, Kim Y, Wood TK. (2008). Protein translation and cell death: the role of rare tRNAs in biofilm formation and in activating dormant phage killer genes. PLoS ONE 3: e2394.

González Barrios AF, Zuo R, Hashimoto Y, Yang L, Bentley WE, Wood TK. (2006a). Autoinducer 2 controls biofilm formation in Escherichia coli through a novel motility quorum sensing regulator (MqsR, B3022). J Bacteriol 188: 305-316.

González Barrios AF, Zuo R, Ren D, Wood TK. (2006b). Hha, YbaJ, and OmpA regulate Escherichia coli $\mathrm{K} 12$ biofilm formation and conjugation plasmids abolish motility. Biotechnol Bioeng 93: 188-200.

Herzberg M, Kaye IK, Peti W, Wood TK. (2006). YdgG (TqsA) controls biofilm formation in Escherichia coli $\mathrm{K}-12$ by enhancing autoinducer 2 transport. J Bacteriol 188: $587-598$.

Hong S-J, Lessner FH, Mahen EM, Keiler KC. (2007). Proteomic identification of tmRNA substrates. Proc Natl Acad Sci USA 104: 17128-17133.

Hou Y-M. (1999). Transfer RNAs and pathogenicity islands. Trends Biochem Sci 24: 295-298.

Iuchi S, Chepuri V, Fu HA, Gennis RB, Lin EC. (1990). Requirement for terminal cytochromes in generation of the aerobic signal for the arc regulatory system in 
Escherichia coli: study utilizing deletions and lac fusions of cyo and cyd. J Bacteriol 172: 6020-6025.

Kirby JE, Trempy JE, Gottesman S. (1994). Excision of a P4like cryptic prophage leads to Alp protease expression in Escherichia coli. J Bacteriol 176: 2068-2081.

Kitagawa M, Ara T, Arifuzzaman M, Ioka-Nakamichi T, Inamoto $\mathrm{E}$, Toyonaga $\mathrm{H}$ et al (2005). Complete set of ORF clones of Escherichia coli ASKA library (a complete set of E. coli K-12 ORF archive): unique resources for biological research. DNA Res 12: 291-299.

Lee J, Jayaraman A, Wood TK. (2007). Indole is an inter-species biofilm signal mediated by SdiA. BMC Microbiol 7: 42

Lindsey DF, Mullin DA, Walker JR. (1989). Characterization of the cryptic lambdoid prophage DLP12 of Escherichia coli and overlap of the DLP12 integrase gene with the tRNA gene $\arg U$. J Bacteriol 171: 6197-6205.

Maeda T, Sanchez-Torres V, Wood TK. (2008). Metabolic engineering to enhance bacterial hydrogen production. Microb Biotechnol 1: 30-39.

Muramoto K, Kawagishi I, Kudo S, Magariyama Y, Imae Y, Homma M. (1995). High-speed rotation and speed stability of the sodium-driven flagellar motor in Vibrio alginolyticus. J Mol Biol 251: 50-58.

Nieto JM, Madrid C, Prenafeta A, Miquelay E, Balsalobre $\mathrm{C}$, Carrascal $\mathrm{M}$ et al (2000). Expression of the hemolysin operon in Escherichia coli is modulated by a nucleoid-protein complex that includes the proteins Hha and H-NS. Mol Gen Genet 263: 349-358.

Osterhout R, Figueroa I, Keasling J, Arkin A. (2007). Global analysis of host response to induction of a latent bacteriophage. BMC Microbiol 7: 82.

Pfaffl MW. (2001). A new mathematical model for relative quantification in real-time RT-PCR. Nucl Acids Res 29: e45.

Pfeiffer T, Schuster S, Bonhoeffer S. (2001). Cooperation and competition in the evolution of ATP-producing pathways. Science 292: 504-507.

Pratt LA, Kolter R. (1998). Genetic analysis of Escherichia coli biofilm formation: roles of flagella, motility, chemotaxis and type I pili. Mol Microbiol 30: 285-293.

Ren D, Bedzyk LA, Setlow P, Thomas SM, Ye RW, Wood TK. (2004a). Gene expression in Bacillus subtilis surface biofilms with and without sporulation and the importance of $y v e R$ for biofilm maintenance. Biotechnol Bioeng 86: 344-364.

Ren D, Bedzyk LA, Thomas SM, Ye RW, Wood TK. (2004b). Differential gene expression shows natural brominated furanones interfere with the autoinducer-2 bacterial signaling system of Escherichia coli. Biotechnol Bioeng 88: 630-642.

Ren D, Bedzyk LA, Thomas SM, Ye RW, Wood TK. (2004c). Gene expression in Escherichia coli biofilms. Appl Microbiol Biotechnol 64: 515-524.

Rice SA, Tan CH, Mikkelsen PJ, Kung V, Woo J, Tay M et al. (2009). The biofilm life cycle and virulence of Pseudomonas aeruginosa are dependent on a filamentous prophage. ISME J 3: 271-282.
Rodriguez RL, Tait RC. (1983). Recombinant DNA Techniques: An Introduction. Benjamin/Cummings Publishing: Menlo Park, CA.

Sambrook J, Fritsch EF, Maniatis T. (1989). Molecular Cloning, A Laboratory Manual 2nd edn. Cold Spring Harbor Laboratory Press: Cold Spring Harbor, NY.

Sozhamannan S, Chute MD, McAfee FD, Fouts DE, Akmal A, Galloway DR et al (2006). The Bacillus anthracis chromosome contains four conserved, excision-proficient, putative prophages. BMC Microbiol 6: 34 .

Srividhya KV, Krishnaswamy S. (2007). Sub classification and targeted characterization of prophage-encoded two-component cell lysis cassette. J Biosci 32: 979-990.

Stanley NR, Britton RA, Grossman AD, Lazazzera BA. (2003). Identification of catabolite repression as a physiological regulator of biofilm formation by Bacillus subtilis by use of DNA microarrays. J Bacteriol 185: 1951-1957.

Thompson JF, de Vargas LM, Koch C, Kahmann R, Landy A. (1987). Cellular factors couple recombination with growth phase: characterization of a new component in the lambda site-specific recombination pathway. Cell 50: 901-908.

Tian Y, Wang Q, Liu Q, Ma Y, Cao X, Guan L et al (2008). Involvement of LuxS in the regulation of motility and flagella biogenesis in Vibrio alginolyticus. Biosci Biotech Biochem 72: 1063-1071.

Trempy JE, Kirby JE, Gottesman S. (1994). Alp suppression of Lon: dependence on the $\operatorname{slp} A$ gene. J Bacteriol 176: 2061-2067.

Velicer GJ, Yu Y-t N. (2003). Evolution of novel cooperative swarming in the bacterium Myxococcus xanthus. Nature 425: 75-78.

Vivero A, Banos RC, Mariscotti JF, Oliveros JC, Garcia-del Portillo F, Juarez A et al (2008). Modulation of horizontally acquired genes by the Hha-YdgT proteins in Salmonella enterica serovar Typhimurium. J Bacteriol 190: 1152-1156.

Watnick P, Kolter R. (2000). Biofilm, city of microbes. J Bacteriol 182: 2675-2679.

Webb JS, Givskov M, Kjelleberg S. (2003a). Bacterial biofilms: prokaryotic adventures in multicellularity. Curr Opin Microbiol 6: 578-585.

Webb JS, Lau M, Kjelleberg S. (2004). Bacteriophage and phenotypic variation in Pseudomonas aeruginosa biofilm development. J Bacteriol 186: 8066-8073.

Webb JS, Thompson LS, James S, Charlton T, TolkerNielsen T, Koch B et al (2003b). Cell death in Pseudomonas aeruginosa biofilm development. J Bacteriol 185: 4585-4592.

Whiteley M, Bangera MG, Bumgarner RE, Parsek MR, Teitzel GM, Lory S et al (2001). Gene expression in Pseudomonas aeruginosa biofilms. Nature 413: 860-864.

Wood TK, González Barrios AF, Herzberg M, Lee J. (2006). Motility influences biofilm architecture in Escherichia coli. Appl Microbiol Biotechnol 72: 361-367.

Supplementary Information accompanies the paper on The ISME Journal website (http://www.nature.com/ismej) 